\title{
Rate of passage of digesta in sheep
}

\section{2.* The effect of level of food intake on digesta retention times and on water and electrolyte absorption in the large intestine}

\author{
BY W. L. GROVUM† AND J. F. HECKER \\ Department of Physiology, School of Rural Science, University of New \\ England, Armidale, NSW 235I, Australia \\ (Received 20 Zuly 1971 - Accepted 23 February 1973)
}

\begin{abstract}
I. Three groups of sheep receiving 400,800 and $1200 \mathrm{~g}$ lucerne chaff/d in equal hourly meals were killed. The large intestines were removed and divided into segments $15 \mathrm{~cm}$ long to provide information on the amounts and dry-matter contents of digesta and on the rates of passage of digesta and absorption of water along the large intestine.

2. With increasing intakes of food, increases were observed along the entire large intestine in the amounts of wet digesta present, in the transit rates of digesta and in the rates of absorption of water. 'The mean retention time of digesta in the large intestine decreased with increasing food intake, being 1737,1056 and $692 \mathrm{~min}$ respectively.

3. Four patterns of sodium and potassium concentrations in digesta water along the large intestine were found.
\end{abstract}

Coombe \& Kay (1965) injected markers into the ileum of sheep through fistulas and showed that the retention times of these markers in the large intestine were decreased by increasing the level of food intake. In other experiments with sheep the times for $5 \%$ excretion of markers, administered as single injections into the rumen, were also decreased by increasing the level of intake of long roughage (Lambourne, 1957; Raymond, Minson \& Harris, 1959; Graham \& Williams, I962). These changes in $5 \%$ excretion times indicate a faster 1 ate of passage of marker through the gut distal to the reticulo-rumen (Balch, 1950). As the retention times of marker in the small intestine of sheep were relatively small and not greatly affected by the level of food intake (Coombe \& Kay, I965; Grovum \& Williams, I973), the decrease in $5 \%$ times must have resulted mainly from a faster passage of digesta through the large intestine.

Hecker \& Grovum (r97I) determined the rate of passage of digesta and the rates of water and electrolyte absorption along the large intestines of sheep given $800 \mathrm{~g}$ lucerne chaff/d. The purpose of the experiment now reported was to study the effect of level of food intake on these characteristics.

\section{EXPERIMENTAL}

The seven sheep given $400 \mathrm{~g}$ and the six sheep given $\mathrm{I} 200 \mathrm{~g}$ lucerne chaff were those used in the study of the small intestine reported by Grovum \& Williams (r973), and details of the sheep, their housing and feeding are described there. The results

* Paper no. I: Br. J. Nutr. (1973), 29, 13.

+ Present address: Department of Animal Science, University of Manitoba, Winnipeg, Manitoba, Canada. 
reported by Hecker \& Grovum (I97I) for six sheep given $800 \mathrm{~g}$ lucerne chaff/d have been supplemented with results for two additional sheep.

The length of the large intestine, wet and dry weights of digesta, retention time and transit rate of digesta, calculated lumen diameter and surface area of the large intestine and the electrolyte concentration in digesta were determined by the methods of Hecker \& Grovum (1971).

The total faecal outputs and their dry-matter contents for each sheep were measured over $5 \mathrm{~d}$.

The rates of water absorption from parts of the large intestine were also measured; the method of Hecker \& Grovum (1971) was called method I. In addition, method 2 (equation I) was used for calculation of the rate of water absorption in the caecum and proximal colon in $\mathrm{g} / 100 \mathrm{~cm}^{2}$ per $\mathrm{min}$ :

$$
\text { rate }=\frac{\left(W_{i}-W_{s}\right) a}{A \times T} \times \frac{100}{\mathrm{I}} .
$$

$W_{i}$ and $W_{s}$ were weight of water $(\mathrm{g})$ per $\mathrm{g}$ dry matter in digesta in the terminal ileum and at the start of the spiral colon respectively, and $a, A$ and $T$ were the amount of dry matter in, the surface area of, and the retention time of digesta in the caecum and proximal colon respectively.

In the presentation of the results, the large intestine has been considered to consist of five sections, each $20 \%$ of the total length. These are the caecum and proximal colon, centripetal colon, centrifugal colon, subterminal colon, and terminal colon. Statistical comparisons between results for sheep given different amounts of food were made by analysis of variance and the sequential variant of the $\mathrm{Q}$ method. Probabilities of less than 0.05 were taken to be significant.

\section{RESULTS}

\section{Length of the large intestine, wet and dry weight of digesta and retention times}

The lengths of the large intestine (Table I) were not significantly correlated with either the live weights of the sheep or food intake.

There were significantly more wet digesta in the large intestine of sheep given 1200 $\mathrm{g}$ food/d than in those given $400 \mathrm{~g}$ (Table $\mathrm{I}$ ). There were significant positive correlations between the weights of wet digesta in each of the five sections of the large intestine as well as the total and food intake. The differences between treatments in the dry-matter contents of the large intestine were significant in only two sections.

The retention times of digesta in all sections of the large intestine were significantly shorter for larger food intakes (Table $\mathrm{r}$ ). The retention times were longest in the caecum and proximal colon and shortest in the spiral colon for each level of food intake.

\section{Transit rates of digesta}

Larger food intakes were associated with faster mean transit rates along the length of the large intestine except in the terminal colon where the rates were similar for the sheep given 400 and $800 \mathrm{~g}$ lucerne chaff (Fig. I). The fastest transit rates were in the spiral colon for each level of intake. 
Table I. Lengths of sections, and weights and retention times of digesta in the sections of the large intestine of sheep given 400,800 or $1200 \mathrm{~g}$ lucerne chaff/d ( $n=7,8$ and 6 respectively)

\begin{tabular}{|c|c|c|c|c|c|c|}
\hline \multirow[b]{2}{*}{ Food intake } & \multicolumn{5}{|c|}{ (Mean values with their standard errors) } & \multirow[b]{2}{*}{ Total } \\
\hline & $\begin{array}{l}\text { paecum and } \\
\text { proximal } \\
\text { colon }\end{array}$ & $\begin{array}{l}\text { Centripetal } \\
\text { colon }\end{array}$ & $\begin{array}{l}\text { Centrifugal } \\
\text { colon }\end{array}$ & $\begin{array}{l}\text { Subterminal } \\
\text { colon }\end{array}$ & $\begin{array}{l}\text { Terminal } \\
\text { colon }\end{array}$ & \\
\hline \multicolumn{7}{|c|}{ Length $(\mathrm{cm})$} \\
\hline 400 & $87 \pm 7 \cdot 2$ & $99 \pm 5 \cdot 3$ & $\operatorname{Ir} 2 \pm 9 \cdot 4^{2}$ & \multicolumn{2}{|c|}{$200 \pm 14.0$} & $498 \pm 25 \cdot 7^{\mathrm{a}}$ \\
\hline 800 & $80 \pm 6 \cdot 7$ & $88 \pm 7 \cdot 4$ & $92 \pm 5.7$ & \multicolumn{2}{|c|}{$192 \pm 9.5$} & $450 \pm 23 \cdot 3$ \\
\hline $\begin{array}{l}\text { I } 200 \\
F \dagger\end{array}$ & $98 \pm 8 \cdot 2$ & $92 \pm 7 \cdot 3$ & ${ }_{*}^{124 \pm 3 \cdot 3^{c}}$ & \multicolumn{2}{|c|}{$226 \pm 15 \cdot 5$} & $537 \pm \pm_{*}^{1} 5 \cdot 1$ \\
\hline \multicolumn{7}{|c|}{ Wet weight $(\mathrm{g})$} \\
\hline 400 & $711 \pm 68 \cdot 3^{\mathrm{a}}$ & $55 \pm 4 \cdot 9^{a}$ & $39 \pm 5 \cdot 7^{\mathrm{a}}$ & $37 \pm 4^{2} 2^{a}$ & $70 \pm 9 \cdot I^{a}$ & $912 \pm 80 \cdot 8^{a}$ \\
\hline 800 & $745 \pm 46 \cdot 3^{b}$ & $67 \pm 3 \cdot 2$ & $50 \pm 3 \cdot 2$ & $50 \pm 3.9$ & $123 \pm 13 \cdot 4$ & $1034 \pm 49.5^{b}$ \\
\hline $\begin{array}{l}1200 \\
F \dagger\end{array}$ & $956 \pm 4+4 \cdot \circ$ & $8 \mathrm{r} \pm 6 \cdot 9$ & $6 \mathrm{I} \pm 4.5$ & $59 \pm 8 \cdot 2$ & $124 \pm \pm_{* *}^{13} 5^{c}$ & $1282 \pm 51 \%$ \\
\hline \multicolumn{7}{|c|}{ Dry weight $(\mathrm{g})$} \\
\hline 400 & $104 \pm 155$ & IO $\pm \mathbf{I} \cdot \mathbf{I}$ & $9 \pm I \cdot I^{a}$ & I I $\pm I \cdot I$ & $25 \pm 3 \cdot 8^{\mathrm{a}}$ & $160 \pm 12 \cdot 5$ \\
\hline 800 & $91 \pm 6.7$ & $12 \pm 0.4$ & $12 \pm 0.7^{c}$ & I $5 \pm I \cdot 4$ & $47 \pm 6 \cdot 4$ & $176 \pm 12 \cdot 4$ \\
\hline $\begin{array}{l}1200 \\
F \uparrow\end{array}$ & I $16 \pm 7 \cdot 8$ & $12 \pm I \cdot 2$ & $\underset{*}{13 \pm 0.8}$ & $16 \pm 1 \cdot 6$ & $\underset{*}{4 I \pm 4 \cdot 9}$ & $200 \pm 9.4$ \\
\hline \multicolumn{7}{|c|}{ Retention time (min) } \\
\hline $\begin{array}{l}400 \\
800\end{array}$ & $\begin{array}{c}\operatorname{Iog} 8 \pm 130 \cdot 0^{2} \\
568 \pm 3^{6} \cdot 7^{\mathrm{b}}\end{array}$ & $\begin{array}{r}\operatorname{II} 3 \pm 9 \cdot 4^{\mathrm{a}} \\
67 \pm 2 \cdot 8^{b}\end{array}$ & $\begin{array}{c}110 \pm 15^{\cdot 8^{a}} \\
67 \pm 4 \cdot 2^{b}\end{array}$ & $\begin{array}{c}124 \pm 14 \cdot 0^{a} \\
81 \pm 6 \cdot 7^{b}\end{array}$ & $\begin{array}{l}292 \pm 44 \cdot 5^{\mathrm{a}} \\
273 \pm 37 \cdot 8\end{array}$ & $\begin{array}{l}1737 \pm 166 \cdot 0^{a} \\
1056 \pm 58 \cdot 0^{b}\end{array}$ \\
\hline $\begin{array}{l}1200 \\
F+\end{array}$ & $407 \pm 40 \cdot 8$ & $44 \pm \frac{3 \cdot 3^{c}}{* * *}$ & $47 \pm 3 * 3$ & $5_{* * *}^{6 \pm 6 \cdot 5}$ & $139 \pm 15.9^{\circ}$ & $\begin{array}{c}692 \pm 44 \cdot 5^{\mathrm{c}} \\
* * *\end{array}$ \\
\hline
\end{tabular}

a, $b, c$ : Significant differences $(P<0.05)$ between pairs of means as follows: the greatest and the least (a), the greatest and the intermediate (b), the intermediate and the least (c).

+ Significance levels of $F$ in the analysis of variance: $P<0.05$, ** $P<0.01, * * * P<0.005$.

\section{Water content of digesta}

The mean water contents of ileal digesta were $12 \cdot 5 \pm 0.6$ (SE), I0.6 \pm 0.3 and $12 \cdot 0 \pm$ $0.1 \mathrm{~g} / \mathrm{g}$ dry matter for the sheep given 400,800 and $\mathrm{I} 200 \mathrm{~g}$ food respectively. These water contents were significantly greater than those of the caecum. There was a decrease in water content of digesta from the caecum to the rectum in each group of sheep (Fig. 2). The sheep given $1200 \mathrm{~g}$ food had significantly more water in the digesta along the first $60 \%$ of the large intestine than those with the other two intakes (Fig. 2). The differences between the values for sheep given 400 and $800 \mathrm{~g}$ were not significant except in the terminal $5 \%$ of the gut. The correlation between the water content of digesta in the rectum and food intake was not significant. Also, the water content of digesta in the rectum of sheep given either 400,800 or $1200 \mathrm{~g}$ food was not significantly correlated with the retention time of digesta in the large intestine.

Grooves were observed in the digesta that had less than about $5^{\cdot 1} \mathrm{~g}$ water/g dry matter. Pellets were distinctly formed when the digesta contained about $3.6 \mathrm{~g}$ water $/ \mathrm{g}$ dry matter. These values were not affected by the level of food intake. 


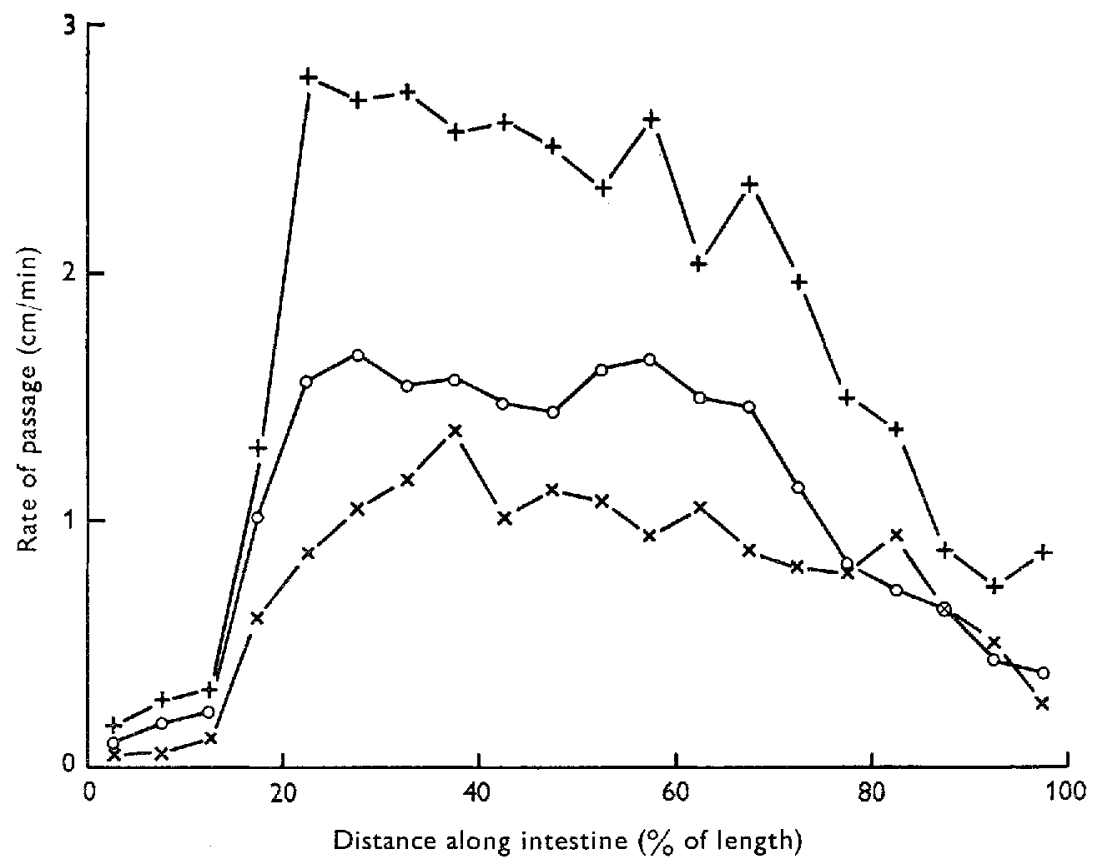

Fig. I. Effect of food intake on the mean rate of passage of digesta along the large intestine of sheep given $(x) 400 \mathrm{~g} / \mathrm{d}(n=7),(0) 800 \mathrm{~g} / \mathrm{d}(n=8)$, or $(+)$ r $200 \mathrm{~g} / \mathrm{d}(n=6)$.

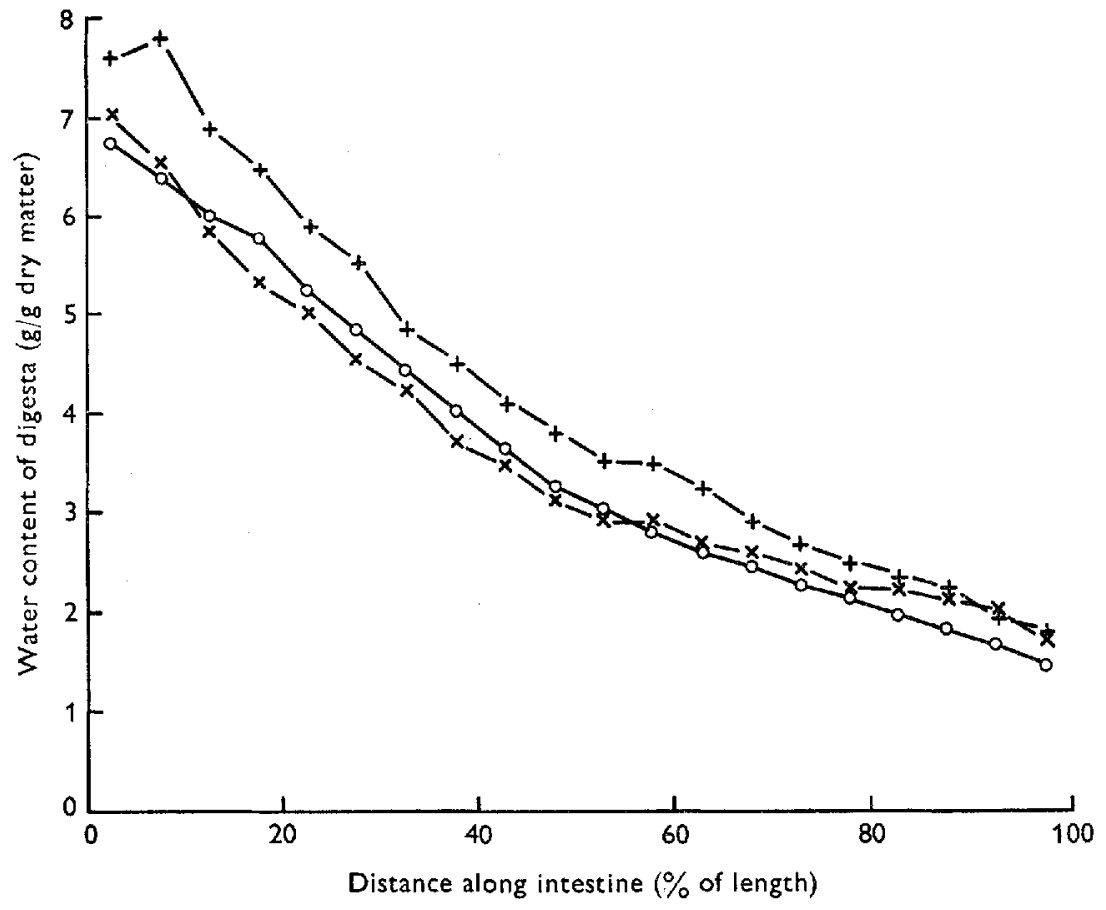

Fig. 2. Effect of food intake on mean water contents of digesta along the large intestine of sheep given $(\times) 400 \mathrm{~g} / \mathrm{d}(n=7)$, (0) $800 \mathrm{~g} / \mathrm{d}(n=8)$, or $(+) 1200 \mathrm{~g} / \mathrm{d}(n=6)$. 


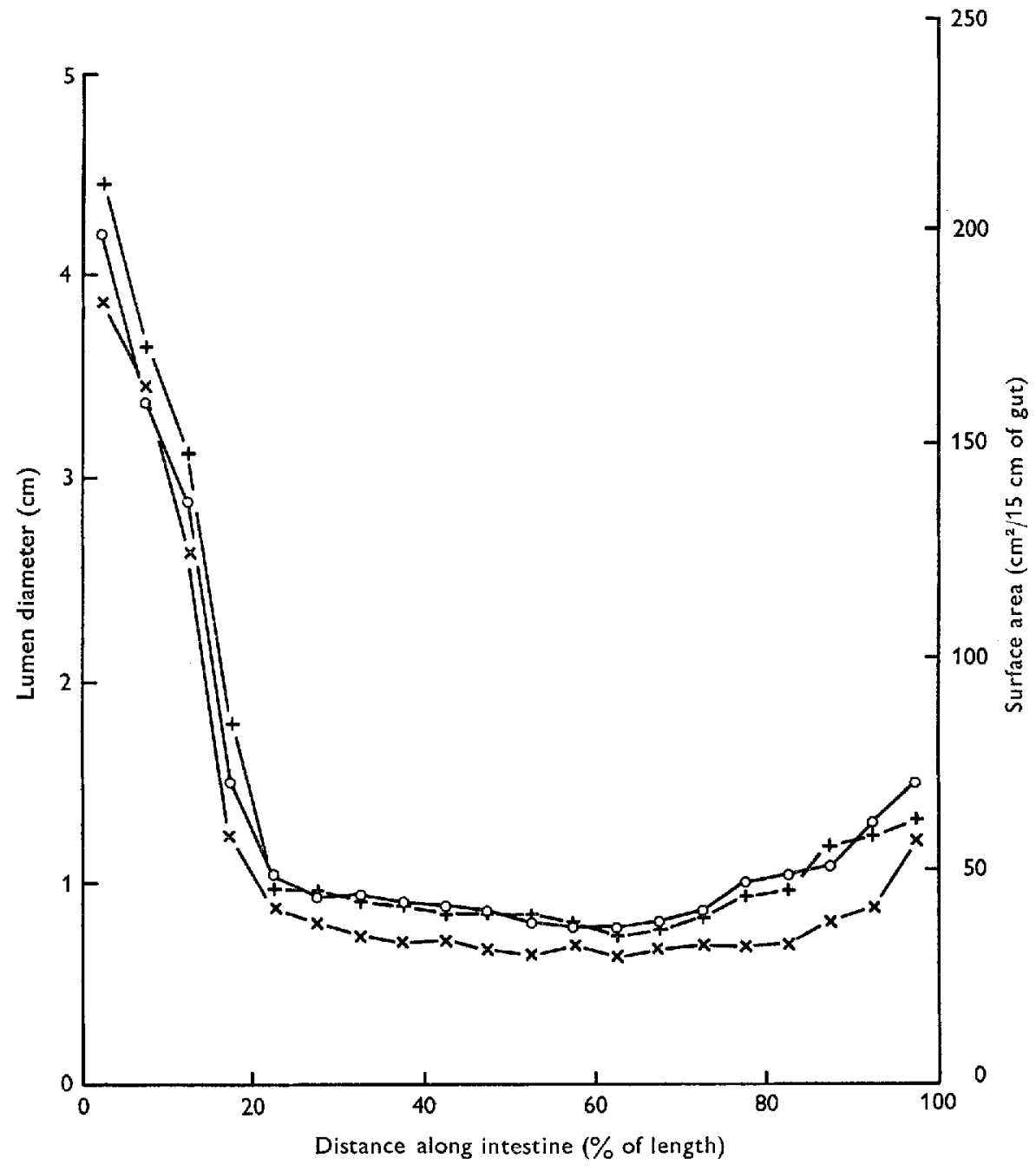

Fig. 3. Effect of food intake on calculated lumen diameter or mucosal surface area along the large intestine of sheep given $(\times) 400 \mathrm{~g} / \mathrm{d}(n=7),(0) 800 \mathrm{~g} / \mathrm{d}(n=8)$, or $(+) \mathrm{r} 200 \mathrm{~g} / \mathrm{d}$ $(n=6)$.

\section{Calculated lumen diameter or surface area}

The lumen diameter or surface area of the caecum and proximal colon increased as the level of food intake increased (Fig. 3), but the differences were not significant. In the remainder of the large intestine, except the rectum, these characteristics were greater in the sheep given 800 and $1200 \mathrm{~g}$ than in those given $400 \mathrm{~g}$. The differences between the values for sheep with the two higher intakes were not significant.

\section{Calculated mucosal surface area}

The total surface areas of the large intestine were $1842 \pm \mathrm{II9}$ (SE), I959 \pm 82 and $2357 \pm 72 \mathrm{~cm}^{2}$ for sheep given 400,800 and $1200 \mathrm{~g}$ respectively. The mean for the I $200 \mathrm{~g}$ group was significantly greater than that for the other two groups $(P<0.05)$. 


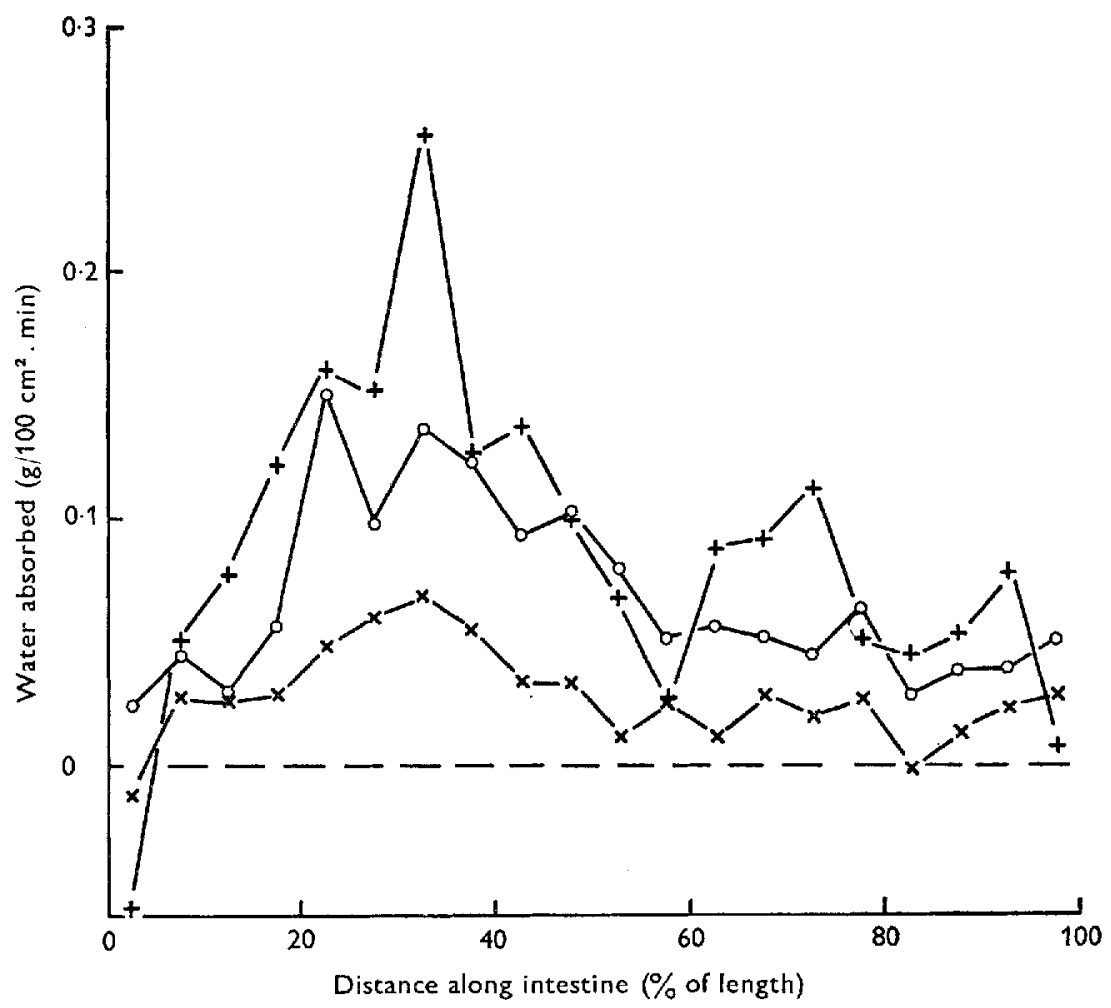

Fig. 4. Effect of food intake on the rates of water absorption per unit calculated mucosal surface area along the large intestine of sheep given $(x)_{400} \mathrm{~g} / \mathrm{d}(n=7),(0) 800 \mathrm{~g} / \mathrm{d}(n=8)$, or $(+) 1200 \mathrm{~g} / \mathrm{d}(n=7)$.

\section{Rates of absorption of water}

The rate of water absorption from the large intestine, calculated by method $\mathbf{I}$, tended to increase as the food intake increased (Fig. 4). The differences between the sheep given 400 and $1200 \mathrm{~g}$ were most marked. The rates in the caecum and proximal colon calculated by this method were small. They were greatest in the spiral colon and tended to decrease towards the rectum.

The mean rates of water absorption in the caecum and proximal colon calculated by method 2 were $0.068 \pm 0.022$ (SE), $0.116 \pm 0.004$ and $0.155 \pm 0.004 \mathrm{~g} / 100 \mathrm{~cm}^{2}$ per min for sheep given 400,800 and $\mathrm{I} 200 \mathrm{~g}$ food respectively. The value for the $400 \mathrm{~g}$ food intake was significantly less than that for the other two intakes $(P<0.05)$.

\section{Electrolyte concentrations}

The concentrations of sodium and potassium per $g$ dry digesta decreased from the most proximal segment in the caecum to the most distal segment in the rectum (Table 2). The changes were greater for sodium than for potassium. The changes in electrolyte concentrations between the caecum and the rectum were not significantly affected by the level of food intake.

Four patterns of sodium and potassium concentrations in digesta water were found 
Table 2. Concentrations of sodium and potassium in dry matter of digesta obtained from the large intestine of sheep given 400,800 or $1200 \mathrm{~g}$ lucerne chaff $/ d(n=7,6$ and 6 respectively)

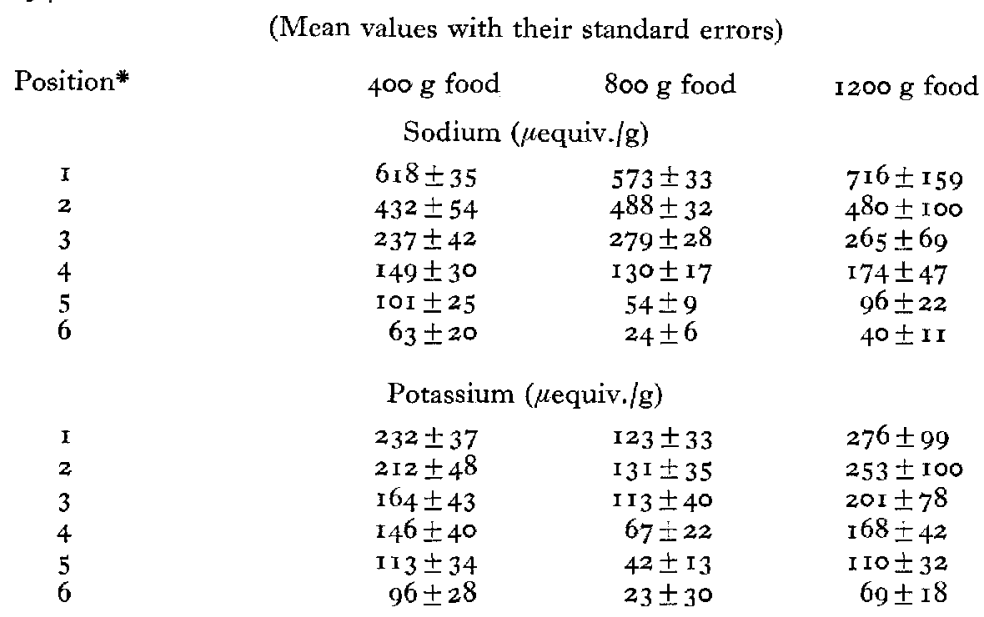

* The caecum ( 1 ), the start, apex and end of the spiral colon (2-4), the mid-point between the end of the spiral colon and the rectum (5), and the rectum or terminal segment of the large intestine (6).

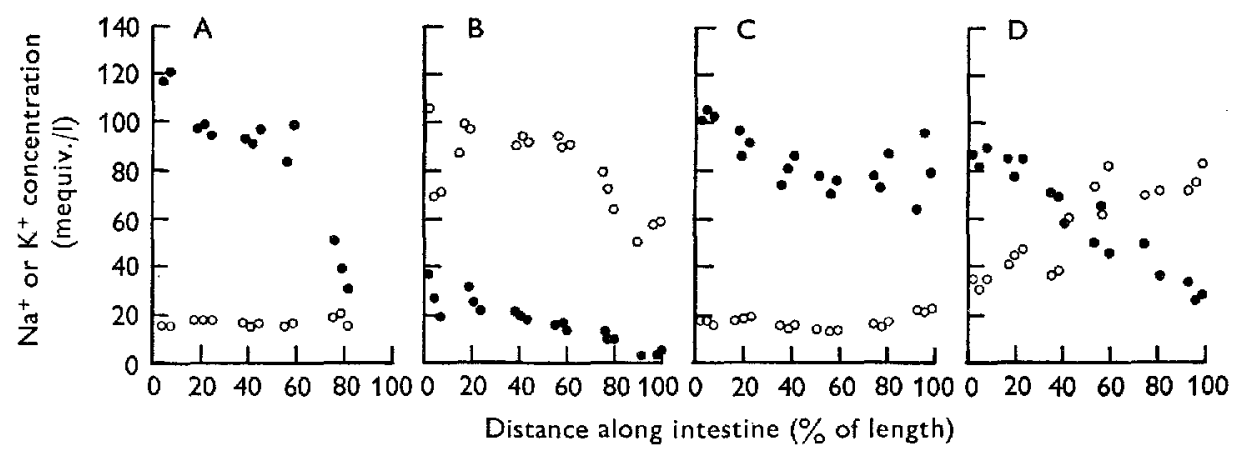

Fig. 5. Patterns of sodium and potassium concentrations in digesta water along the large intestine of sheep. $A$, seven sheep; $B$, four sheep; $C$, one sheep; $D$, one sheep. (C) sodium concentration; $(O)$ potassium concentration.

in the shecp given 400 and $1200 \mathrm{~g}$; representative results for each pattern are shown in Fig. 5. Three sheep given $400 \mathrm{~g}$ and four receiving $\mathrm{I} 200 \mathrm{~g}$ had low potassium concentrations; the sodium concentrations decreased between the caecum and the rectum (part A). Two sheep with each of these intakes had low sodium concentrations and high potassium concentrations (part B), and another given $400 \mathrm{~g}$ food had high sodium and low potassium concentrations (part C). In the other sheep, with $400 \mathrm{~g}$ food, the sodium concentration decreased and the potassium concentration increased along the large intestine (part D). 


\section{DISCUSSION}

The sheep used in this experiment were allocated to the food treatments without regard to sex. Ewes constituted four out of seven sheep given $400 \mathrm{~g}$ food/d and one out of six sheep given $I 200 \mathrm{~g}$. In this paper, the differences in results between treatments have been interpreted as mainly effects of level of food intake rather than sex.

The difference in the water content of digesta between the ileum and the caecum was probably due to mixing of digesta in, and absorption of water from, the caecum and proximal colon (Hecker \& Grovum, I97I). If the contents had been completely mixed, they would have been homogeneous. However, the gradient in the concentration of water per $g$ dry matter in the caecum and proximal colon indicates that mixing occurred but that it was not complete. Faichney (1969) came to a similar conclusion while studying the rates of production of volatile fatty acids in the caecum and proximal colon of the sheep. This mixing would result in an underestimation of the rate of water absorption for the caecum and proximal colon as calculated by method I but would not affect the rate as calculated by method 2 .

The greater rates of flow of digesta through the gut associated with the larger intakes of food were apparently accommodated to a limited extent in the large intestine by an increase in lumen diameter or mucosal surface area (Fig. 3). The lumen diameters in the last $80 \%$ of the large intestine of the sheep given 800 and $\mathrm{I} 200 \mathrm{~g}$ were similar but larger than those in the sheep given $400 \mathrm{~g}$. The transit rates of digesta beyond the caecum and proximal colon were markedly greater in the sheep given $1200 \mathrm{~g}$ food/d than in those given $800 \mathrm{~g}$ (Fig. I), indicating that the removal of undigested food residues from the alimentary tract at larger food intakes was facilitated more by an increase in propulsive motility of the large intestine than by distension or an increase in its lumen diameter. The upper physiological limits to distension or propulsive motility are unknown.

Some caution is required in interpreting the measurements of lumen diameter and surface area of the large intestine because it was difficult to free the large intestine from its mesentery without a small amount of stretching. Thus the significant difference between the lengths of the centrifugal colon (Table I) may have been due to disproportionate stretching. The method does not account for small folds in the mucosa or for gas in the digesta of the proximal large intestine and between the pellets in the rectal region. The actual lumen diameters and mucosal surface areas in these sections of the intestine will therefore be underestimated.

The retention time of digesta in the large intestine was less for the larger food intakes. This was also found by Coombe \& Kay $(1965)$. The present study has shown that the transit rates of digesta were faster or that the retention times were shorter in all sections of the large intestine of sheep with larger food intakes. However, the digesta spent the longest time in the caecum and proximal colon, and the decrease in the retention time of digesta due to increases in food intake were greatest in this section. Thus the caecum and proximal colon probably contributed most to the total decrease in marker retention times in the large intestine due to increases in food intake.

Four patterns of electrolyte concentrations in digesta water were observed in this 
experiment. Hecker \& Grovum (I97I) reported that five out of six sheep given $800 \mathrm{~g}$ lucerne chaff showed changes in electrolyte concentration in digesta water similar to that in part A of Fig. 5. The results for their sixth sheep showed changes in sodium concentration similar to that in part $\mathrm{A}$, but the potassium concentration increased from the caecum to the apex of the spiral colon and then decreased to a low value in the rectum. The results for this sheep, therefore, give an additional pattern of electrolyte changes in the large intestine. A pattern for sodium and potassium similar to that shown in part D for one sheep was found in fifteen sheep by Pfeffer \& Christen (1969).

The sheep given $\mathrm{I} 200 \mathrm{~g}$ absorbed approximately 3.8 times as much water from the large intestine per $\mathrm{d}$ as those given $400 \mathrm{~g}$ (Grovum \& Williams, 1973). The decreases in electrolyte concentrations per $\mathrm{g}$ of dry matter between the caecum and the rectum were similar for all food intakes (Table 2). Therefore, the sheep given $1200 \mathrm{~g}$ must have absorbed at least three times as much sodium and potassium as the sheep given $400 \mathrm{~g}$. This would account for the increased quantities of water absorbed at the higher intakes if one assumes that water absorption was linked to active sodium transport. Sodium must have been actively absorbed, since its concentration in digesta water (Fig. 5) was always less than the value of about 145 mequiv./ lexpected for plasma.

The water contents of digesta in the rectum and the differences in water content of digesta between the terminal ileum and the rectum were essentially the same for the I200 and the $400 \mathrm{~g}$ food intakes even though the retention time of digesta in the large intestine was markedly less in the sheep given $1200 \mathrm{~g} / \mathrm{d}$ (Table $\mathrm{r}$ ). The rates of water absorption from the large intestine per day or per unit of retention time were greater in the sheep given $1200 \mathrm{~g}$ than in those given $400 \mathrm{~g}$. This phenomenon may also be explained by the rapid absorption of sodium from digesta in the large intestine. The results presented for the moisture content of digesta (Fig. 2) and the concentration of sodium in dry digesta along the length of the large intestine (Table 2) are similar to those published by Pfeffer \& Christen (I969) for sheep. However, they found that the concentration of potassium in dry digesta did not change greatly along the large intestine from a value of about $10.8 \mathrm{mg} / \mathrm{g}$, which is similar in magnitude to that shown in Table 2 for the caecum. In our sheep the concentration of potassium in dry digesta decreased distally along the large intestine.

There were no marked differences in the concentrations of sodium and potassium in digesta water between the food intake groups. Devroede \& Phillips (I969, I970) perfused the human large intestine with isotonic solutions containing polyethylene glycol and sodium chloride and found that increasing the infusion rate from 5 to ro $\mathrm{ml} / \mathrm{min}$ caused more water to be absorbed from the colon even though the mean transit time of the marker was reduced. This increase in the rate of water absorption per unit of retention time could have resulted from an increase in the surface area available for absorption, or an increase in pore size in the mucosa. However, changes in the mucosal surface area were apparently not responsible for the increased rate in the sheep in this experiment because water absorption was expressed per unit of marker retention time and per unit of surface area. Thus, in humans and in sheep, the rate of water absorption from the large intestine may be affected primarily by the ability of the large bowel to absorb sodium. 
In our work the water content of the faeces was not related to the quantity of lucerne chaff given nor to the retention time of digesta in the large intestine. These results do not agree with those of Castle (1956a,b,c) or Blaxter, Graham \& Wainman (1956), who worked with goats and sheep respectively. No explanation for the different findings can be given.

The small and large intestines accommodate increased flows of digesta resulting from increased food intake by distending to accept a greater volume of digesta and by increasing the transit rate of digesta (decreasing its retention time). However, the decrease in the retention time of digesta in the large intestine with increased food intake was much greater in magnitude than that for the small intestine (Grovum \& Williams, r973).

W.L.G. is grateful to the Australian Government for financial support under the Commonwealth Scholarship and Fellowship Plan.

\section{REFERENCES}

Balch, C. C. ( 950 ). Br. .7. Nutr. 4, 36r.

Blaxter, K. L., Graham, N. McC. \& Wainman, F. W. (1956). Br. \%. Nutr. 1o, 69.

Castle, E. J. (1956a). Br. F. Nutr. Io, I 5 .

Castle, E. J. (1956b). Br. ₹. Nutr. 10, 1 15.

Castle, E. J. (1956c). Br. $\mathscr{~}$. Nutr. 10, 338 .

Coombe, J. B. \& Kay, R. N. B. (1965). Br. F. Nutr. 19, 325.

Devroede, G. J. \& Phillips, S. F. (I969). Gastroenterology 56, 92.

Devroede, G. J. \& Phillips, S. F. (1970). Gut I1, 438 .

Faichney, G. J. (1969). Aust. $\mathcal{~}$. agric. Res, 20, 491.

Graham, N. McC. \& Williams, A. J. (1962). Aust. F. agric. Res. 13, 894 .

Grovum, W. L. \& Williams, V. J. (1973). Br. F. Nutr. 29, т 3.

Hecker, J. F. \& Grovum, W. L. (1971). Aust. F. biol. Sci. 24, 365.

Lambourne, L. J. (1957). F. agric. Sci., Camb. 48, 273.

Pfeffer, E. \& Christen, V. v. (1969). Z. Tierphysiol. Tierernähr. Futtermittelk. 25, 344.

Raymond, W. F., Minson, D. J. \& Harris, C. E. (1959). F. Br. Grassld Soc. 14, 75. 